\title{
Physiologically Based Dissolution Testing in a Drug Development Process-a Case Study of a Successful Application in a Bioequivalence Study of Trazodone ER Formulations Under Fed Conditions
}

\author{
Dorota Danielak, ${ }^{1,6}$ Bartłomiej Milanowski, ${ }^{2}$ Krzysztof Wentowski, ${ }^{3}$ Maria Nogowska, ${ }^{3}$ Michał Kątny, ${ }^{3}$ \\ Piotr Rogowski, ${ }^{3}$ Lukasz Konwicki, ${ }^{3}$ Ewa Puk, ${ }^{3}$ Jarosław Pieczuro, ${ }^{3}$ Marek Bawiec, ${ }^{4}$ \\ Grzegorz Garbacz, ${ }^{5}$ and Janina Lulek ${ }^{2}$
}

Received 26 November 2019; accepted 13 March 2020; published online 2 June 2020

\begin{tabular}{|c|}
\hline 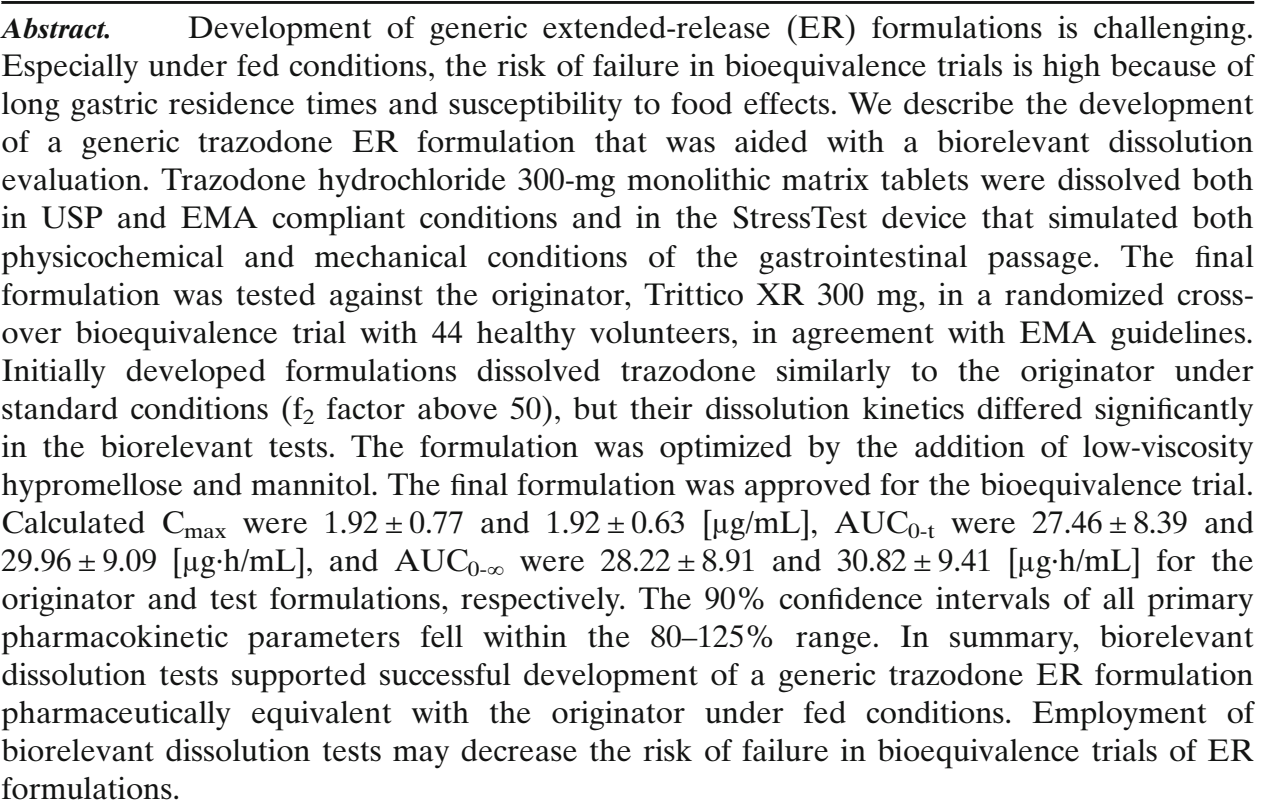 \\
\hline
\end{tabular}

KEY WORDS: Trazodone; Generic; Bioequivalence; Extended release; Biorelevant dissolution.

Electronic supplementary material The online version of this article (https://doi.org/10.1208/s12249-020-01662-8) contains supplementary material, which is available to authorized users.

${ }^{1}$ Department of Physical Pharmacy and Pharmacokinetics, Faculty of Pharmacy, Poznan University of Medical Sciences, 6 Święcickiego st, 60-781, Poznań, Poland.

${ }^{2}$ Department of Pharmaceutical Technology, Faculty of Pharmacy, Poznan University of Medical Sciences, 6 Grunwaldzka st, 60-780, Poznań, Poland.

${ }^{3}$ Biofarm Sp. z o.o, 13 Wałbrzyska st, 60-198, Poznań, Poland.

${ }^{4}$ Institute of Computer Engineering, Control and Robotics, Wroclaw University of Technology, 27 Wybrzeże Wyspańskiego st, 50-370, Wrocław, Poland.

${ }^{5}$ Physiolution GmbH, Walther-Rathenau Strasse 49a, 17489, Greifswald, Germany.

${ }^{6}$ To whom correspondence should be addressed. (e-mail: danielak@ump.edu.pl)

\section{INTRODUCTION}

The global pharmaceutical market requires high-quality generic drugs. Solely in the USA, approximately $90 \%$ of prescribed drugs are generic; at the same time, they account for less than a quarter of total expenses on prescription drugs (1). In 2018, savings from generic drug prescription amounted to 292.6 billion dollars in the USA alone (2). Pharmaceutical companies are required to prove bioequivalence of the manufactured generic drug with a brand name product unless the regulatory agency approves biowaiver. This process is time- and cost-consuming. Therefore, the sponsor of the study should make all the efforts to develop a formulation that will ensure the success of the pharmacokinetic bioequivalence trial. Drug pharmacokinetics differs both within and between subjects due to physiological conditions such as sex, age, or genetic polymorphisms of enzymes involved in the metabolism of xenobiotics. Therefore, variability of 
drug dissolution should be as low as possible. Also, drug release from generic formulation should resemble the brand name product as closely as possible under fasted and fed conditions, if applicable. It is even more critical in modified (MR) and extendedrelease (ER) formulations. As the ER forms are designed to release the active ingredient over prolonged time, they are prone to food effects (3). Koziolek et al. (3) distinguished three categories of food effects relevant for MR and ER dosage forms: (i) drugrelated factors including partition coefficient, stability in different $\mathrm{pH}$ values, or absorption rate; (ii) formulation-related factors comprising dose, size, excipients, and drug release profiles; and (iii) physiology-related factors including gastrointestinal motility, specific $\mathrm{pH}$ profile, gastric emptying, or food composition and caloric content. Novel test methods allow the in vitro evaluation of drug dissolution profiles under physiologically relevant conditions. They allow the use of media simulating the composition of fluids in human gastrointestinal tract, such as simulated gastric fluid (SGF) or simulated intestinal fluid (SIF) (4). Additionally, devices such as Dissolution Stress Test (5) or a Fed Stomach Model (6) can effectively simulate shear stresses generated by peristaltics during gastrointestinal passage. As shown in the SmartPill@ studies, these contractions generate pressure up to 500 mbar, especially in the antro-pyloric region during gastric emptying (7).

Since the drug delivery of ER products is often dependent on their geometry, the simulation of mechanical stresses in dissolution tests, such as simulated motility forces or dynamic events of transport, can effectively point dissimilarities between ER formulations under biorelevant conditions (8). Different susceptibility of formulations to mechanical stress in vivo can cause irregular drug release and increase pharmacokinetic variability $(9,10)$. Therefore, advanced dissolution stress devices can aid the successful development of high-quality generic drugs.

In this paper, we demonstrate the development of a generic trazodone ER formulation. Trazodone is a weak base. This Biopharmaceutics Classification System (BCS) Class II drug is sparingly soluble in water, and its experimentally evaluated $\log \mathrm{P}$ is 2.9 (11). It is also $\mathrm{pH}$ sensitive with a $\mathrm{pK}_{\mathrm{a}}$ of about 6.74 (12). Trazodone is most commonly used as a salt of hydrochloric acid.

The novelty of the study is an intensive use of biopredictive, physiology-mimicking dissolution tests during the formulation development process, leading to a successful bioequivalence trial under fed conditions. Until now, the usefulness of the StressTest device was used for the development of novel, pressure-sensitive dosage forms (13) or for an explanation of observed fluctuations in the pharmacokinetics of drugs administered as ER formulations (10). Therefore, the paper presents a new application of the device for bioequivalent generic drug development.

\section{MATERIALS AND METHODS}

\section{Reagents}

\section{Trazodone Formulations}

Generic trazodone hydrochloride ER tablets (Trazodon XR $300 \mathrm{mg}$ ), containing $300 \mathrm{mg}$ of the active ingredient (equivalent to $273.2 \mathrm{mg}$ of trazodone), were manufactured by a direct compression method. The dissolution profiles of the active substance were tested along with the brand name product-Trittico XR $300 \mathrm{mg}$ (Aziende Chimiche Riunite Angelini Francesco A.C.R.A.F. S.p.A.). Six batches, labeled A to $\mathrm{F}$, were tested in biorelevant conditions. The qualitative composition of each analyzed batch is available in Table I. The amount of the active ingredient-trazodone-did not exceed $35 \%$ of total tablet mass.

\section{Dissolution Media}

In the development process, both standard and biorelevant media were used. Standard media included $0.1 \mathrm{M}$ hydrochloric acid with $2.92 \mathrm{~g} / \mathrm{L}$ sodium chloride $(\mathrm{pH}=1.2)$ and $50 \mathrm{mM}$ phosphate buffer $\mathrm{pH}=6.0$. Biorelevant media were $50 \mathrm{mM}$ phosphate buffer at $\mathrm{pH}$ ranging from 4.5 down to 1.8 (with the addition of $\mathrm{HCl}$ ), and $50 \mathrm{mM}$ phosphate buffer $\mathrm{pH}=6.5$ with FaSSIF (Fasted State Simulated Intestinal Fluid)/FeSSIF (Fed State Simulated Intestinal Fluid)/ FaSSGF (Fasted State Simulated Gastric Fluid) powder (Biorelevant.com Ltd., London, UK) in a concentration corresponding to a fed state. All of the reagents were of analytical grade.

\section{Dissolution Tests}

Each tablet batch was preliminarily tested in a standard dissolution media. Then, it was investigated further in biorelevant conditions resembling fed state. In all biorelevant tests, the dissolution profiles of trazodone from generic formulations were compared with the originator. If the dissolution profile differed significantly from the originator, reformulation and further characterization were performed. The batch with the dissolution profile most comparable with the brand name product was qualified for use in the clinical bioequivalence trial.

\section{Standard Dissolution Tests}

Standard dissolution tests were performed in a conventional USP dissolution apparatus 2 (Agilent VK7025 and Agilent 708 DS) with a constant paddle rotation at $150 \mathrm{rpm}$, according to "Guideline on quality of oral modified release products" issued by European Medicines Agency (EMA) (14). The tablets were placed in USP compliant Japanese basket sinkers. The conditions used for dissolution studies were based on a Trazodone once daily patent documentation, No. US7829120B2 (12). Initially, the dissolution medium was $0.1 \mathrm{M}$ hydrochloric acid with $2.92 \mathrm{~g} / \mathrm{L}$ sodium chloride $(\mathrm{pH}=$ 1.2). After $1 \mathrm{~h}$, the medium was exchanged to a $50-\mathrm{mM}$ phosphate buffer $\mathrm{pH}=6.0$. Dissolution profiles were determined for $24 \mathrm{~h}$. Collected samples were assayed with a highperformance liquid chromatography method, validated according to "Validation of Analytical Procedures: Text and Methodology" guidelines developed by the ICH (15). The chromatographic separation was performed on an XBridge C18 column $3.5 \mu \mathrm{m}, 75 \times 4.6 \mathrm{~mm}$ (Waters, MA, USA), using acetonitrile and trifluoroacetic acid $(0.2 \%)(35: 65 ; \mathrm{v} / \mathrm{v})$ as a mobile phase, at the isocratic flow rate of $1.2 \mathrm{~mL} / \mathrm{min}$. The total run time was $2 \mathrm{~min}$, the injection volume was $5.0 \mu \mathrm{L}$, and the detection (UV-Vis) wavelength was set at $246 \mathrm{~nm}$. The column temperature was maintained at $25^{\circ} \mathrm{C}$. Additionally, an 
Table I. Composition of Developed Formulations Tested in Biorelevant Dissolution Tests. For All of the Ingredients Besides Trazodone Hydrochloride, the Values Are Presented as Mass Percentages of the Total Mass of the Tablet

\begin{tabular}{lllllr}
\hline Ingredient & A & B & C & D & E \\
\hline Trazodone hydrochloride (mg) & 300 & & & \\
Hypromellose 100,000 (\%) & $16-19$ & $21-24$ & $21-24$ & $5-10$ & $5-10$ \\
Hypromellose 4000 (\%) & - & - & - & $5-10$ & $5-10$ \\
Microcrystalline cellulose (\%) & $20-25$ & $20-25$ & $15-20$ & $23-32$ & $20-26$ \\
Silicified microcrystalline cellulose (\%) & $20-25$ & $15-20$ & $15-20$ & $16-19$ & $16-19$ \\
Mannitol (\%) & - & - & $3-8$ & -10 & $3-6$ \\
Talc (\% & $1-2$ & & & $3-26$ \\
Magnesium stearate (\%) & $1-2$ & Yes & Yes & No & No \\
Polyvinyl coating & Yes & & & Yes \\
\hline
\end{tabular}

$\mathrm{f}_{2}$ similarity factor was calculated, according to the EMA guideline (16). The $\mathrm{f}_{2}$ values greater than 50 ensured the equivalence of both test and originator products in standard dissolution studies.

\section{Biorelevant Dissolution Tests}

Stress Test Device. The dissolution stress test device was first introduced by G. Garbacz and W. Wetschies (9). The core principle of the StressTest device is to simulate the mechanical agitation of physiological intensity that acts on a solid dosage form during the GI transit as well as the physicochemical conditions in the subsequent sections of the GI. A detailed description of the device is given elsewhere (5).

Test Setup Parameters. Dissolution tests were designed to simulate the fed intake conditions of the bioequivalence trial. First, the medium was $1100 \mathrm{~mL} 50 \mathrm{mM}$ phosphate buffer at $\mathrm{pH} 4.5$. The $\mathrm{pH}$ of the medium was gradually decreased to 1.8 by addition of $5 \mathrm{M}$ hydrochloric acid; then, after $5 \mathrm{~h}$ the $\mathrm{pH}$ was adjusted to $\mathrm{pH} 6.5$ by the addition of $40 \%$ sodium hydroxide, and $40 \mathrm{~mL}$ of a FaSSIF/FeSSIF/FaSSGF concentrate solution in a $50 \mathrm{mM}$ phosphate buffer concentrate was added $(77.9 \mathrm{~g}$ of the powder in a $50 \mathrm{mM}$ phosphate buffer, filled up to a final volume of $240 \mathrm{~mL}$, stirred until dissolved, and allowed to settle for at least $1 \mathrm{~h}$ before addition to the media). The final concentration of the FaSSIF/FeSSIF/ FaSSGF in the simulated intestinal fluid was $11.2 \mathrm{~g} / \mathrm{L}$, corresponding to the fed state. The media change pattern was aligned with the simulation of the mechanical aspects of the GI tract. The stress program was set up. Figure 1 presents stress as well as the media type and change pattern used in the present biorelevant dissolution studies.

Determination of Trazodone in Biorelevant Media. The amount of the drug dissolved was determined every $10 \mathrm{~min}$ using online closed-loop UV-Vis spectroscopy. The samples were filtered through a PES (polysulfone) filter with a pore size of $1 \mu \mathrm{m}$ (Sartorious, Göttingen, Germany) and analyzed in a flow-through mode. Flow-through quartz cuvettes of a 5mm path length (Hellma, Müllheim, Germany) were used with an Agilent 8543 spectrophotometric system (Agilent, Santa Clara, USA) with the photometers set to a differential mode at two wavelengths of $\lambda=313 \mathrm{~nm}$ for trazodone signal and $\lambda=450 \mathrm{~nm}$ for the background, respectively.

\section{Bioequivalence Study}

The bioequivalence study was a single-center, singledose, open-label (laboratory blinded), randomized, fourperiod, four-way cross-over study, according to the "Guideline on the pharmacokinetic and clinical evaluation of modified release dosage forms" (EMA/CPMP/EWP/280/96 Corr1) (17). The protocol of the study was approved by the Independent Ethics Committee at the Regional Chamber of Physicians in Warsaw, and by the Office for Registration of Medicinal Products, Medical Devices and Biocidal Products in Poland. The trial was registered in the EU Clinical Trial Register under the number 2018-000598-57.

Sustained and predictable release of the drug from the ER dosage is more challenging in fed conditions than in a fasted state, both in dissolution studies and in the proper setup of the clinical study protocol. Therefore, in this paper, we will present the results of the bioequivalence trial performed under fed conditions only.

\section{Study Group}

The minimum sample size needed to adequately assess the bioequivalence of two trazodone formulations was calculated as suggested by Diletti et al. (18). Based on the reported clinical studies NCT00839072 (19) and NCT01121900 (20), the $\mathrm{C}_{\max }$ of trazodone after administration of $300 \mathrm{mg}$ trazodone hydrochloride varies intraindividually by approximately $29 \%$. Assuming the power of the test at $80 \%$ and significance level $\alpha=0.05$, the bioequivalence assessment required at least 38 subjects.

The study included forty-four healthy subjects of both sexes. The characteristics of the study group are presented in Table II. Each subject signed an Informed Consent Form. Before and during the study, the subjects had to refrain from the use of other drugs, products containing nicotine, alcohol, caffeine, or grapefruit juice. Each subject had the right to withdraw from the study. The participation of a subject might have been discontinued for reasons including adverse events and study protocol deviation. 

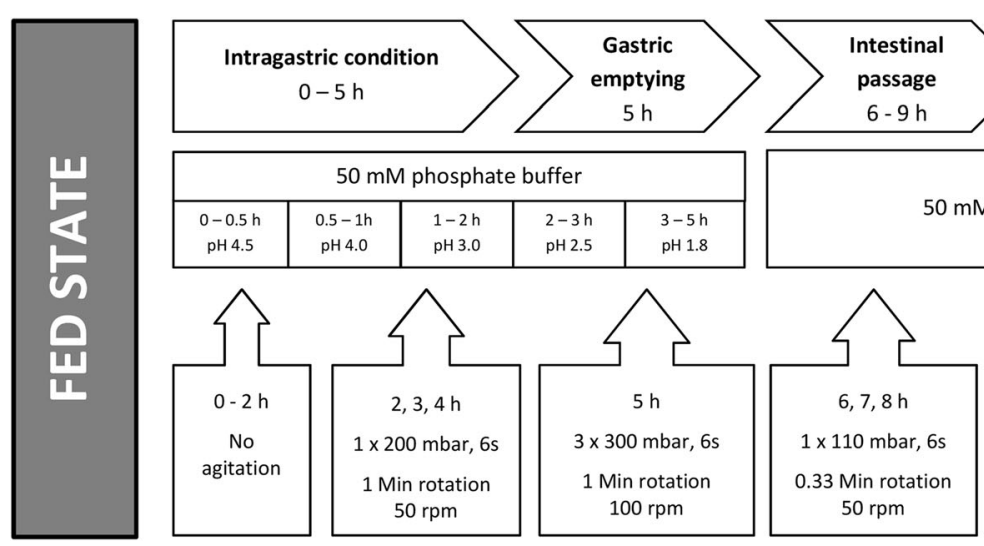

50 mM Phosphate buffer pH $6.5+$ FeSSIF

Fig. 1. Setup of the program for biorelevant dissolution tests

\section{Protocol}

A single dose of the test product (Trazodon XR $300 \mathrm{mg}$ ) or the brand name product (Trittico XR $300 \mathrm{mg}$ ), both containing $300 \mathrm{mg}$ trazodone hydrochloride, was administered by the oral route. The administration was within $30 \mathrm{~min}$ after the start of a standardized high-fat meal, with $250 \mathrm{~mL}$ of still, room temperature water. No other fluid intake was allowed from $2 \mathrm{~h}$ before until 1-h post-dosing. Additionally, fluids were administered as follows: $250 \mathrm{~mL}$ of fluid with breakfast, $150 \mathrm{~mL}$ of still water at 1,2 , and $3 \mathrm{~h}$ postadministration, $200 \mathrm{~mL}$ fluid with meals at 4 and $12 \mathrm{~h}$ postadministration, and $100 \mathrm{~mL}$ at $5,6,7,8,9,10$, and $11 \mathrm{~h}$ postadministration. Standardized lunch and supper were served at about 4 and $12 \mathrm{~h}$ after drug administration.

From each subject $4 \mathrm{~mL}$ of full blood was collected before drug administration (time "0"), and at 1, 2, 3, 4, 5, 6, 8, $9,10,11,12,13,14,15,16,20,24,28,32,36,42,48$, and $72 \mathrm{~h}$ after the intake of the drug. The blood samples were taken before the intake of fluids. Full blood was collected through heparinized capillaries into a vacuum blood collection system. Immediately after collection, the samples were centrifuged, and the plasma was transferred into separate tubes, stored in dry ice, and shipped into the laboratory for trazodone determination. Any deviations from the sampling protocol were noted, and the actual sampling times were reported for further analysis.

\section{Determination of Trazodone Concentrations and Pharmacokinetic Parameter Calculations}

Plasma samples were shipped in dry ice to an external, certified laboratory for the determination of trazodone. The drug concentrations were determined with a high-

Table II. Characteristics of the Study Group. Data Are Presented as Means \pm Standard Deviations

\begin{tabular}{lll}
\hline Parameter & Female $(n=11)$ & Male $(n=33)$ \\
\hline Age (years) & $39.3 \pm 11.4$ & $33.4 \pm 9.3$ \\
Weight $(\mathrm{kg})$ & $66.0 \pm 7.4$ & $74.5 \pm 8.3$ \\
Body mass index $\left(\mathrm{kg} / \mathrm{m}^{2}\right)$ & $23.8 \pm 2.8$ & $23.4 \pm 2.1$ \\
\hline
\end{tabular}

performance liquid chromatography mass spectrometry method (LC-MS), in a multiple reaction monitoring mode (MRM). The method was validated according to the EMA guidelines in terms of selectivity, accuracy, and precision (21). The lower limit of trazodone quantitation was $10 \mathrm{ng} / \mathrm{mL}$.

The pharmacokinetic evaluation was planned in agreement with the guideline CPMP/EWP/QWP/1401/98 Rev. 1/Corr** (16) and EMA/CPMP/EWP/280/96 Corr1 (17). Following pharmacokinetic parameters were considered for bioequivalence evaluation: area under the time-concentration curve from time 0 to $72 \mathrm{~h}\left(\mathrm{AUC}_{0-\mathrm{t}}\right)$, area under timeconcentration curve extrapolated to infinity $\left(\mathrm{AUC}_{0-\infty}\right)$, and maximum concentration obtained directly from the measured concentrations $\left(\mathrm{C}_{\max }\right)$. Additional secondary parameters included time to $\mathrm{C}_{\max }\left(\mathrm{T}_{\max }\right)$ and plasma half-life $\left(\mathrm{T}_{1 / 2}\right)$ that was calculated from $0.693 / \mathrm{K}_{\mathrm{el}}$, where $\mathrm{K}_{\mathrm{el}}$ represents the elimination rate constant determined through a linear regression. Of note, only the actual sampling times were used. The parameters were calculated by the linear-log trapezoidal rule in Phoenix WinNonlin software, build 8.1.0.3530 (Certara USA, Princeton, NJ, USA).

Bioequivalence after a single dose of trazodone $300 \mathrm{mg}$ under fed conditions was established upon a ratio of test and reference product parameters. Before the analysis, the parameters were log-transformed. The $90 \%$ confidence interval for the ratio should be contained within 80.00 $125.00 \%$. The pharmacokinetic parameters were analyzed with ANOVA test, with factors for sequence, subject within sequence, period, and treatment. Also, the Schuirmann's two one-sided parametric $\mathrm{T}$ tests were calculated with the null hypothesis of bioinequivalence at the $5 \%(\alpha=0.05)$ level of significance.

\section{RESULTS}

\section{Standard Dissolution Tests}

The release profiles of trazodone from tested formulations are presented in Fig. 2. All of the tablets release the active substance steadily over $24 \mathrm{~h}$. Most of the formulations released less than $30 \%$ of trazodone within the first hour, no less than $70 \%$ after $12 \mathrm{~h}$, and at least $80 \%$ after $24 \mathrm{~h}$ from the beginning of the dissolution study. The originator released trazodone slower than any of the tested formulations. Batches $\mathrm{A}, \mathrm{B}$, and $\mathrm{C}$ resembled most the release profile of the 
originator. In contrast, batches $\mathrm{D}$, and $\mathrm{E}$ released the active ingredient at a noticeably faster rate. This observation also holds for the final batch $\mathrm{F}$ that was the model for the clinical batch. The calculated $\mathrm{f}_{2}$ factors were as follows: batch $\mathrm{A}=$ 51.4 , batch $\mathrm{B}=72.3$, batch $\mathrm{C}=69.0$, batch $\mathrm{D}=32.9$, batch $\mathrm{E}=$ 33.8 , batch $\mathrm{F}=44.3$.

\section{Dissolution Tests in Biorelevant Conditions}

First developed batches-A, B, and C-resembled the trazodone release profile of the originator during the first $5 \mathrm{~h}$ (Fig. 3). However, the drug release changed noticeably after the introduction of 300 mbar stress mimicking the gastric emptying and transition from gastric to intestinal media. The mechanical stress affected the dissolution of the originator more than all of the tested batches. Susceptibility of the originator to the events of the mechanical stress of biorelevant fortitude caused a faster release of trazodone and the complete dissolution of tablet matrices. At the same time, the generic matrices resisted biorelevant mechanical agitation and were deformed only slightly. Therefore, further reformulation was required.

Batches D and E were more similar to the brand name product. The final batch $\mathrm{F}$, that was approved for use in the clinical trial, was developed upon batch E. The only difference between batches $\mathrm{E}$ and $\mathrm{F}$ was a polyvinyl coating that did not influence the release of trazodone from the tablets, as shown in Fig. 3. Batch D was not chosen for further studies because of distinctly different dissolution characteristics under fasted conditions. However, the characterization of drug release under fasted conditions is outside of the scope of this paper.

\section{Clinical Bioequivalence Trial}

Thirty-nine subjects completed the study. As stated above, the trial required a minimum of 38 participants to assess bioequivalence with a sufficient power. Table III presents the calculated pharmacokinetic parameters for both formulations. Both primary and secondary parameters of the test formulation (Trazodon XR $300 \mathrm{mg}$ ) resembled those calculated for the brand name product (Trittico XR $300 \mathrm{mg}$ ). Pharmacokinetic profiles of both formulations were similar (Fig. 4). Individual pharmacokinetic profiles are available in the Online Supplementary Data file (Supplement 1). The intra-subject variability for $\mathrm{AUC}_{0-\mathrm{t}}, \mathrm{AUC}_{0-\infty}$, and $\mathrm{C}_{\max }$ was $11.56 \%, 10.74 \%$, and $22.18 \%$, respectively. The inter-subject variability for $\mathrm{AUC}_{0-\mathrm{t}}, \mathrm{AUC}_{0-\infty}$, and $\mathrm{C}_{\max }$ was $27.80 \%$, $28.83 \%$, and $28.11 \%$, respectively.

ANOVA test showed that the sequence and period effects were negligible for all primary parameters. One of the statistically significant factors was a joint subject and sequence effect. These parameters affected all three primary parameters $(p<0.0001)$. Also, the type of formulation (test product or the brand name product) influenced the exposure to trazodone, expressed as $\mathrm{AUC}_{0-\mathrm{t}}$, and $\mathrm{AUC}_{0-\infty}(p=0.0014$ and $p=0.0005$, respectively). For $\mathrm{C}_{\max }$ this effect was not statistically important $(p=0.5955)$.

The results of the bioequivalence assessment presented in Table IV show that the test product fulfilled the criteria for bioequivalence with the brand name product under fed conditions.

\section{DISCUSSION}

In the present study, we demonstrate how the use of biorelevant methods, i.e., the biorelevant stress test device, supported the development of a generic ER trazodone formulation. The test protocols were utilized to predict the drug delivery behavior of the tested formulations. In this context, the performed study served as a proof-of-concept for the predictive power of the StressTest device. As a result, the developed formulation fulfilled the bioequivalence criteria under fed conditions.

The successful formulation of a generic ER dosage form is a complex and challenging process. In general, if the originator and generic formulations are similar, they should also have similar dissolution characteristics under every condition tested. However, the formulation can be considered as equivalent only if the bioequivalence trial is passed under the same test conditions (fasted and/or fed) as the originator. It becomes challenging if the exposure to the drug differs significantly between fasted and fed states. This phenomenon is observed for trazodone. Karhu et al. (22) showed that pharmacokinetics of a once-daily Trazodone Contramid $300 \mathrm{mg}$ formulation differed significantly between fasted and fed conditions. The AUC between these two states was similar. However, after a high-fat meal, the $\mathrm{C}_{\max }$ of trazodone was $86 \%$ higher compared with fasted conditions. The $\mathrm{C}_{\max }$ values falling outside $80-125 \%$ confidence intervals show that two products are not equivalent.

Consequently, the fed conditions can be considered as more difficult with respect to the development of generics. Therefore, the present paper aims at the description of the product performance under fed conditions. The strict criteria for primary pharmacokinetic parameters obtained in the bioequivalence trial result in setting up requirements for the pharmaceutical development and characterization of oral medicines in the preclinical stage. Such characterization, especially when performed with biorelevant methodology, may reduce the risk of failure and accelerate the development process.

Adequate reflection of luminal conditions requires more than the compendial media. Food ingredients such as lipids, proteins and their digestion products act as natural surfactants affecting both the solubility of the active pharmaceutical ingredient (API), as well as hydration and erosion processes of MR matrices (7). These components are also present in biorelevant media, such as simulated gastric fluid, fed state simulated intestinal fluid, fasted state simulated intestinal fluid, milk, and nutritional drink. Therefore, these media should be used to predict the disintegration of ER matrices $(23,24)$. The type of food also affects the tablet erosion process. In fed conditions the tablets disintegrate slower in comparison with the fasting state, and thus drug dissolution in the stomach is delayed $(25,26)$. For this reason, we adjusted the study protocol to reflect the physico-chemical properties of gastrointestinal fluids more accurately than conventional dissolution media. The media composition and $\mathrm{pH}$ profiles and transit times used in the present study were set according to Koziolek et al. $(27,28)$. 


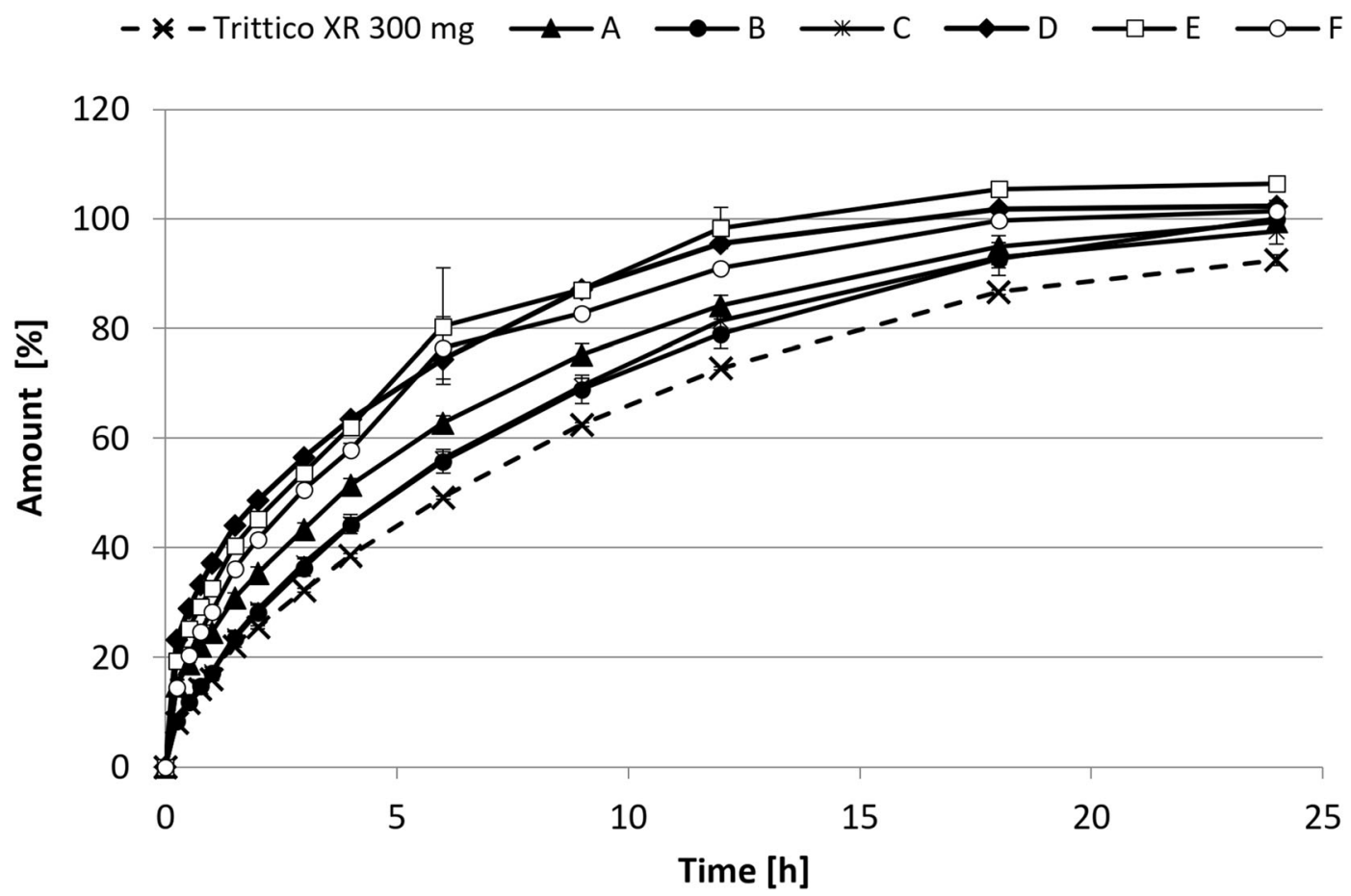

Fig. 2. Trittico XR $300 \mathrm{mg}$ and Trazodon XR $300 \mathrm{mg}$ dissolution profiles obtained in standard dissolution tests, according to USP. Data are presented as means ( $n=4$ for Trittico XR $300 \mathrm{mg}, \mathrm{A}-\mathrm{D}, n=2$ for E-F) with standard deviations as whiskers

The drug delivery behavior of monolithic hydrogel matrix tablets, such as ones developed in this study, may be remarkably affected by the mechanical and hydrodynamical agitation. Motility forces produce such stress during the physiologic events of transport such as gastric emptying, and ileocaecal and colonic passage (29). In some cases, mechanical agitation results in deformation, fast erosion of the tablets matrices, and an increase in the drug delivery rate or even dose dumping $(29,30)$. Such agitation may be more pronounced under fed conditions due to increased motoric activity and passage times through the highly active proximal parts of gastrointestinal tract. Thus, in the present study, we used a test program with differing patterns intended for the simulation of the fed state (Fig. 1). The arrangement of the stress program was derived from the in vivo studies performed using telemetric capsules $(7,27,31)$. For the fed state, moderate 200-mbar intragastric stress events were programmed within the first $2-4 \mathrm{~h}$, followed by the major gastric emptying stress (300 mbar) at $5 \mathrm{~h}$. Then, after the transition to 'intestinal' conditions, regular stress of 110 and 200 mbar was introduced. In summary, the fed conditions proposed in our study (Fig. 1) reflect these in vivo findings according to both composition, residence times, and stress patterns.

All of the tested tablets were monolithic hydrophilic matrix systems. First batches (A-C) consisted mainly of highviscosity hydroxypropyl methylcellulose (hypromellose, HPMC). In the dissolution study performed according to USP, they released the drug steadily, reaching almost $95 \%$ of the dose labeled within $24 \mathrm{~h}$. Subsequent batches, D and E, were characterized by a noticeably faster drug release than batches A-C. In these two batches, the amount of Hypromellose 100000 was decreased to less than $10 \%$ of the total tablet mass, and a low viscosity Hypromellose 4000 was introduced; also, batch $\mathrm{E}$ included a small amount of mannitol. Final batch $F$, which differed from batch $E$ only by a presence of polyvinyl coating, had a comparable dissolution profile. Increased release of the drug was also achieved by increasing the amount of microcrystalline cellulose. Properties of hypromellose may explain observed dissolution performance. Of note, all of the batches tested in the USP apparatus had different dissolution kinetics as compared with the originator, Trittico XR $300 \mathrm{mg}$. As revealed later in the test under biorelevant conditions, the batches with the dissolution profiles that were most similar to the originator performed worse, especially after the transition to media simulating intestinal fluids.

As shown by Conti et al. $(32,33)$, high-viscosity polymers release the drug through a diffusion-controlled mechanism, as expressed by Fick's law, while low viscosity gelling agents promote erosion of the swollen polymer. Poorly water-soluble drugs, such as trazodone under the simulated intestinal conditions, are mostly released through the latter mechanism (34). Additionally, high molecular viscosity polymers may decrease the drug release rate (35). Other properties of hypromellose, such as a higher percentage of hydroxypropoxy groups or particle size, may increase the dissolution rates $(36,37)$. Other excipients used for the preparation of the batches include microcrystalline cellulose and silicified microcrystalline cellulose. They show good binding properties, are compatible with a broad range of drugs, and are physiologically inert; silicified microcrystalline cellulose also has an increased surface area and improved flow characteristics $(38,39)$. Lastly, mannitol can also increase drug release due to the faster uptake of water (40). All of these excipients contributed to an improved dissolution of trazodone from the test tablets. 

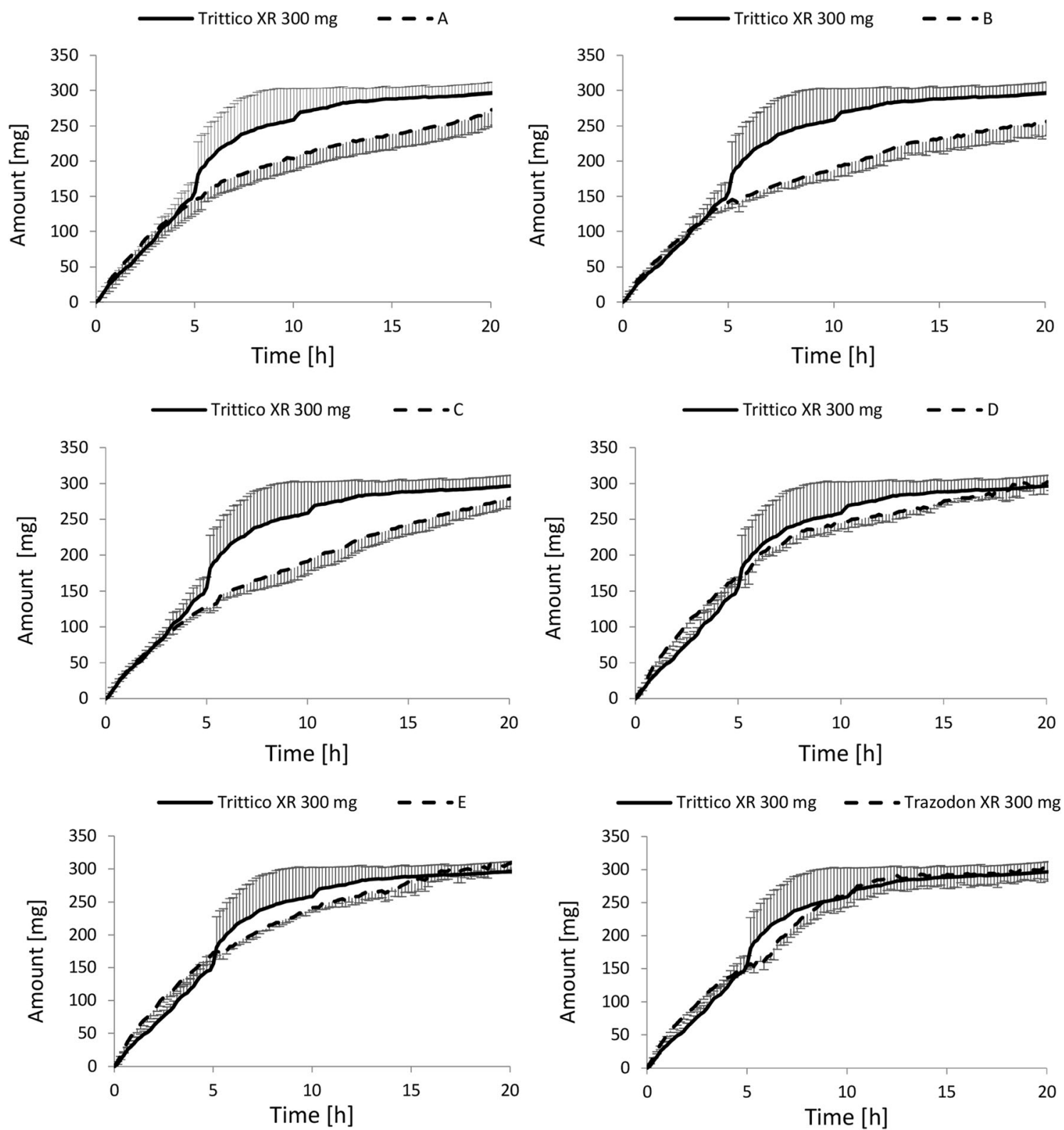

Fig. 3. Dissolution profiles of trazodone from tested Trazodon XR $300 \mathrm{mg}$ batches (A-F) versus Trittico XR $300 \mathrm{mg}$ obtained under simulated fed conditions. Data are presented as means $(n=6)$ with standard deviations as whiskers

Interestingly, the dissolution profile of the originator was characterized by an increased release of the active ingredient after transition to intestinal media (Fig. 3). None of the generic products exhibited such a behavior. Trazodone is a weak base with a $\mathrm{pK}_{\mathrm{a}}=6.74$, and it is most commonly used as trazodone hydrochloride. This salt is sparingly soluble in water, but its solubility increases with an increased acidity of the media (41). Thus, in the upper gastrointestinal tract, where $\mathrm{pH}$ is below trazodone $\mathrm{pK}_{\mathrm{a}}$, it dissolves well. Owing to the high volume, weak buffering capacity of the dissolution

Table III. The pharmacokinetic parameters calculated from the results obtained in the bioequivalence study under fed conditions for the brand name product (Trittico XR $300 \mathrm{mg}$ ) and the test product (Trazodon XR $300 \mathrm{mg})(n=39)$. The data are presented as means \pm standard deviations

\begin{tabular}{|c|c|c|c|c|c|}
\hline Parameter & $\mathrm{C}_{\max }[\mu \mathrm{g} / \mathrm{mL}]$ & $\mathrm{AUC}_{0-\mathrm{t}}[\mu \mathrm{g} \cdot \mathrm{h} / \mathrm{mL}]$ & $\mathrm{AUC}_{0-\infty}[\mu \mathrm{g} \cdot \mathrm{h} / \mathrm{mL}]$ & $\mathrm{T}_{\max }[\mathrm{h}]$ & $\mathrm{T}_{1 / 2}[\mathrm{~h}]$ \\
\hline Trittico XR 300 mg & $1.92 \pm 0.77$ & $27.46 \pm 8.39$ & $28.22 \pm 8.91$ & $7.46 \pm 2.29$ & $9.71 \pm 2.75$ \\
\hline Trazodon XR 300 mg & $1.92 \pm 0.63$ & $29.96 \pm 9.09$ & $30.82 \pm 9.41$ & $7.69 \pm 2.07$ & $9.52 \pm 3.72$ \\
\hline
\end{tabular}

$\mathrm{AUC}_{0-\infty}$ - area under the time-concentration curve extrapolated to infinity, $\mathrm{AUC}_{0-\mathrm{t}}$ - area under the time-concentration curve between time 0 to 72 hours, $\mathrm{C}_{\max }$ - maximum concentration, $\mathrm{T}_{1 / 2}$ - plasma half-life, $\mathrm{T}_{\max }$ - time to maximum concentration 


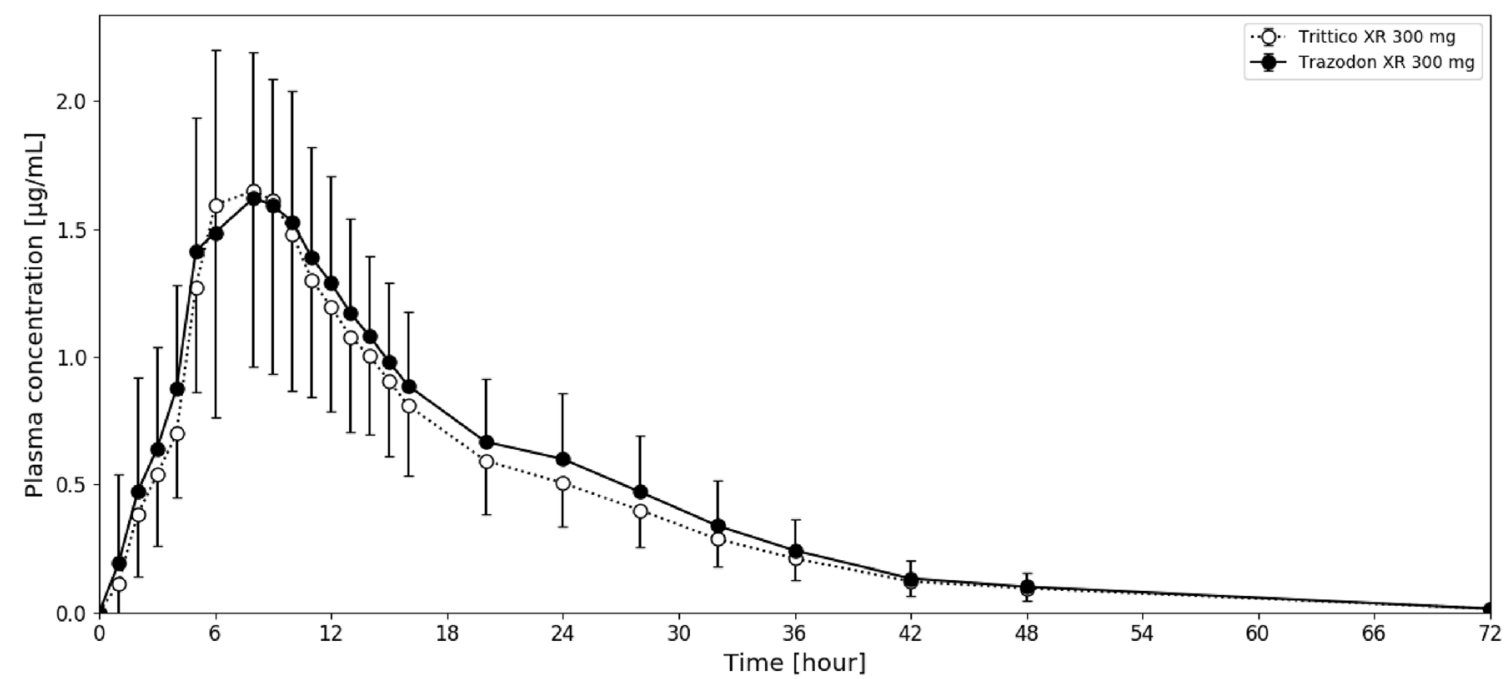

Fig. 4. Pharmacokinetic profiles of Trittico XR $300 \mathrm{mg}$ (originator product) versus Trazodon XR $300 \mathrm{mg}$ (test product). Data are presented as means with standard deviations as whiskers $(n=39)$

media, and presence of natural surfactants, the solubility of trazodone is far below the equilibrium solubility. Solubility of trazodone hydrochloride in the simulated intestinal media estimated during the course of our experiment $(0.15 \mathrm{mg} / \mathrm{mL}$, data not shown) was much lower than in pure water $(18 \mathrm{mg}$ / $\mathrm{mL}$, (41)). Therefore, the higher release of trazodone from Trittico XR $300 \mathrm{mg}$ may result from an extensive stress corresponding to the gastric emptying and it is not an artifact related to the solubility of trazodone. In the case of solubility issues, similar tendencies would also be observed for the generic batches. It underlines a potential advantage of the Stress Test device to discriminate between stress-susceptible and robust extended release dosage forms. In contrast with products developed in the present study, the originator product relies on granulated cross-linked high-amylose starch (Contramide $囚)$, mixed with hypromellose, anhydrous colloidal silica, and sodium stearyl fumarate (42). Contramide swells and forms a rubbery gel, similarly to hypromellose (43), but at the same time it is prone to degradation and erosion caused by $\alpha$-amylase (44). Also, the addition of hypromellose may greatly affect dissolution from cross-linked amylose-based tablets and cause different pharmacokinetic profiles under fasted and fed conditions, as shown by Lenaerts et al. (45). The composition of Trittico XR $300 \mathrm{mg}$ may therefore explain observed differences in the trazodone bioavailability under fasted and fed conditions and underlines the importance of biorelevant conditions for a thorough examination of dissolution profiles during product development and release of the clinical batches.

The study concluded with a successful clinical bioequivalence trial under fed conditions. A statistically significant subject-sequence effect can be explained by a relatively high intra-subject variability in the studied population. The type of formulation (the brand name product $v s$. tested product) was shown to be significant for $\mathrm{AUC}_{0-\mathrm{t}}$ and $\mathrm{AUC}_{0-\infty}$ in the latinsquare ANOVA. However, all of the primary pharmacokinetic parameters fell within the assumed confidence intervals. Therefore, the formulation effect may be considered as negligible, and the two formulations may be concluded as bioequivalent under fed conditions. Besides the development of a formulation with an optimal release profile, the design of the study also contributed to the success in the clinical trial. According to the protocol, not only meals but also fluid intake were tightly scheduled. In the proposed regimen all subjects received a specific liquid volume every hour after administration. A recently established consortium in Understanding Gastrointestinal Absorption-related Processes (UNGAP) investigated the food-drug interactions that may influence the absorption of orally administered drugs (46). According to their state-of-art review, the volume of fluids present in the lumen is one of these factors. First, it influences the concentration-driven passive uptake of the drug and saturable membrane transporters, and second, it exerts an effect on formulation transit times. Another fact is that a standard breakfast is a high-fat energy-rich meal with a high fraction of solids. In stomach it creates a layered, heterogeneous mass that contains layers of solids, fats and fluids (16). Water, a drink of choice in clinical bioequivalence trials, does not mix well with gastric contents rich in fats. Instead, it rapidly follows a so-called stomach road, also known as Magenstrasse, and is emptied from the stomach. In case of ER formulations, this may cause even life-threatening consequences due to dose dumping. Also, ad libitum intake of water during a controlled clinical trial with ER formulations can lead to a "double peak" phenomenon and contribute to the pharmacokinetic variability (47).

Another aspect is tablet residence time and location in the stomach. If a tablet is taken under fed conditions, it may remain in a fundus region of the stomach; this part of the stomach is poorly mixed and acts as storage (48). If the gastric emptying is delayed, the drug is released slowly and accumulates in the proximal stomach (48). Then, after the gastric emptying, it appears in plasma after a long lag phase and at high concentrations. In consequence it may cause erratic pharmacokinetic profiles and ultimately a failure of the bioequivalence trial. Proposed frequent drinking schedule aimed to reduce the risk of drug accumulation in the fundus and significantly contributed to the success of the trial. 
Table IV. Bioequivalence assessment of the test product (Trazodon XR $300 \mathrm{mg}$ ) against the brand name product (Trittico XR $300 \mathrm{mg}$ ). The data are presented as a ratio of pharmacokinetic parameters with $90 \%$ confidence intervals (CI)

\begin{tabular}{|c|c|c|c|c|c|}
\hline Parameter & Ratio (test/reference) & Lower $90 \%$ CI & Schuirmann's $t$-test $p$ value & Upper $90 \%$ CI & Schuirmann's $t$-test $p$ value \\
\hline $\mathrm{AUC}_{0-\mathrm{t}}$ & 109.425 & 104.712 & $<0.0001$ & 111.350 & $<0.0001$ \\
\hline $\mathrm{AUC}_{0-\infty}$ & 109.660 & 105.263 & $<0.0001$ & 114.240 & $<0.0001$ \\
\hline $\mathrm{C}_{\max }$ & 102.694 & 94.444 & $<0.0001$ & 111.664 & 0.0002 \\
\hline
\end{tabular}

$\mathrm{AUC}_{0-\infty}$ - area under time-concentration curve extrapolated to infinity, $\mathrm{AUC}_{0-\mathrm{t}}$ - area under the time-concentration curve between time 0 to 72 hours, $\mathrm{C}_{\max }$ - maximum trazodone concentration

As shown in this study, the development of a pharmaceutically equivalent ER dosage form with a BCS II class active ingredient is a complex process. Simple, compendial methods may not be adequate to ascertain the success in an expensive bioequivalence trial. Also, the use of solely biorelevant media may not be sufficient. In the present study, tested and reference products differed most significantly after the introduction of physiologically relevant stress. Therefore, we confirmed that for monolithic ER formulations the gastrointestinal stress could be an essential element of dosage development. It should be pointed out that all the literature data available so far, describing the usability of the StressTest device, concern only its use for prediction of the dissolution behavior of ER/MR products under fasted conditions. Consequently, the present manuscript represents an original work that describes for the first time the application of the StressTest device and test protocols capable of predicting the in vivo drug delivery behavior under the fed state. The obtained results are supported by the outcome of the clinical trial being a part of the study.

\section{CONCLUSIONS}

In summary, the present study shows that a preclinical development of ER formulations may be aided by advanced dissolution studies that take into account not only the composition of luminal fluids and respective residence times but also timing and fortitude of the physiological mechanical stress that occurs during the gastrointestinal passage.

\section{FUNDING INFORMATION}

This publication was developed as a result of industrial research and development work carried out as part of the project "Implementation of innovative methods for assessing the release and absorption of drugs in the gastrointestinal tract" No. RPWP.01.02.00-30-0021/16, co-financed by the Marshal's Office of the Wielkopolska Region within the Wielkopolska Regional Operational Programme for 20142020 with the support of the European Regional Development Fund. D. Danielak is supported in part by the European Union's Horizon 2020 research and innovation program under the Marie Skłodowska-Curie grant agreement No 778051 "ORBIS - Open Research Biopharmaceutical Internships Support" and the Ministry of Science and Higher Education of Poland fund for supporting internationally cofinanced projects in 2018 to 2022 (agreement No 3899/H2020/ 2018/2). This article reflects the authors' view only.

\section{COMPLIANCE WITH ETHICAL STANDARDS}

Disclaimer Neither the Research Executive Agency nor the Polish Ministry of Science and Higher Education may be held responsible for the use which may be made of the information contained therein.

Conflict of Interest The authors declare no conflict of interest.

Ethics Statement The protocol of the study was approved by the Independent Ethics Committee at the Regional Chamber of Physicians in Warsaw, and by the Office for Registration of Medicinal Products, Medical Devices and Biocidal Products in Poland.

Open Access This article is licensed under a Creative Commons Attribution 4.0 International License, which permits use, sharing, adaptation, distribution and reproduction in any medium or format, as long as you give appropriate credit to the original author(s) and the source, provide a link to the Creative Commons licence, and indicate if changes were made. The images or other third party material in this article are included in the article's Creative Commons licence, unless indicated otherwise in a credit line to the material. If material is not included in the article's Creative Commons licence and your intended use is not permitted by statutory regulation or exceeds the permitted use, you will need to obtain permission directly from the copyright holder. To view a copy of this licence, visit http://creativecommons.org/licenses/by/4.0/.

\section{PUBLISHER'S NOTE}

Springer Nature remains neutral with regard to jurisdictional claims in published maps and institutional affiliations.

\section{REFERENCES}

1. Lionberger R, Uhl K. Generic drugs: expanding possibilities for clinical pharmacology. Clin Pharmacol Ther. 2019;105:278-81. https://doi.org/10.1002/cpt.1320.

2. 2019 Generic Drug and Biosimilars Access \& Savings in the U.S. Report I Association for Accessible Medicines. https:// accessiblemeds.org/resources/blog/2019-generic-drug-andbiosimilars-access-savings-us-report. Accessed 19 Sep 2019. 
3. Koziolek M, Kostewicz E, Vertzoni M. Physiological considerations and in vitro strategies for evaluating the influence of food on drug release from extended-release formulations. AAPS PharmSciTech. 2018;19:2885-97. https://doi.org/10.1208/s12249018-1159-0.

4. Klein S. The use of biorelevant dissolution media to forecast the in vivo performance of a drug. AAPS J. 2010;12:397-406. https://doi.org/10.1208/s12248-010-9203-3.

5. Garbacz G, Klein S, Weitschies W. A biorelevant dissolution stress test device - background and experiences. Expert Opin Drug Deliv. 2010;7:1251-61. https://doi.org/10.1517/ 17425247.2010.527943.

6. Koziolek M, Görke K, Neumann M, Garbacz G, Weitschies W. Development of a bio-relevant dissolution test device simulating mechanical aspects present in the fed stomach. Eur J Pharm Sci. 2014;57:250-6. https://doi.org/10.1016/j.ejps.2013.09.004.

7. Koziolek M, Schneider F, Grimm M, Mode $\beta$ C, Seekamp A, Roustom $\mathrm{T}$, et al. Intragastric $\mathrm{pH}$ and pressure profiles after intake of the high-caloric, high-fat meal as used for food effect studies. J Control Release. 2015;220:71-8. https://doi.org/ 10.1016/j.jconrel.2015.10.022.

8. Garbacz G, Klein S. Dissolution testing of oral modified-release dosage forms. J Pharm Pharmacol. 2012;64:944-68. https:// doi.org/10.1111/j.2042-7158.2012.01477.x.

9. Garbacz G, Wedemeyer R-S, Nagel S, Giessmann T, Mönnikes $\mathrm{H}$, Wilson $\mathrm{CG}$, et al. Irregular absorption profiles observed from diclofenac extended release tablets can be predicted using a dissolution test apparatus that mimics in vivo physical stresses. Eur J Pharm Biopharm. 2008;70:421-8. https://doi.org/10.1016/ j.ejpb.2008.05.029.

10. Garbacz G, Weitschies W. Investigation of dissolution behavior of diclofenac sodium extended release formulations under standard and biorelevant test conditions. Drug Dev Ind Pharm. 2010;36:518-30. https://doi.org/10.3109/03639040903311081.

11. T3DB: Trazodone. Toxin Toxin-Target Database T3DB. http:// www.t3db.ca/toxins/T3D2852. Accessed 10 Jan 2020.

12. Gervais S, Smith D, Rahmouni M, Contamin P, Ouzerourou R, Ma ML, et al. Trazodone composition for once a day administration https://patents.google.com/patent/US7829120B2/ en. Accessed 27 Sep 2019.

13. Wilde L, Bock M, Glöckl G, Garbacz G, Weitschies W. Development of a pressure-sensitive glyceryl tristearate capsule filled with a drug-containing hydrogel. Int J Pharm. 2014;461:296-300. https://doi.org/10.1016/j.ijpharm.2013.11.062.

14. European Medicines Agency. Guideline on quality of oral modified release products. https://www.ema.europa.eu/en/documents/scientific-guideline/guideline-quality-oral-modified-release-products_en.pdf. Accessed 22 Sep 2019

15. Quality Guidelines : ICH. https://www.ich.org/products/guidelines/quality/article/quality-guidelines.html. Accessed $20 \mathrm{Sep}$ 2019.

16. European Medicines Agency. Guideline on the investigation of bioequivalence. https://www.ema.europa.eu/en/documents/scientific-guideline/guideline-investigation-bioequivalencerev1_en.pdf. Accessed 22 Sep 2019.

17. European Medicines Agency. Guideline on the pharmacokinetic and clinical evaluation of modified release dosage forms (EMA/ CPMP/EWP/280/96 Corr1). https://www.ema.europa.eu/en/documents/scientific-guideline/guideline-pharmacokinetic-clinicalevaluation-modified-release-dosage-forms_en.pdf. Accessed 22 Sep 2019.

18. Diletti E, Hauschke D, Steinijans VW. Sample size determination for bioequivalence assessment by means of confidence intervals. Int J Clin Pharmacol. 1991;29:1-8.

19. ClinicalTrials.gov. Comparative bioavailability study of extended-release and immediate-release trazodone in healthy adult volunteers - study results. https://clinicaltrials.gov/ct2/ show/results/NCT00839072. Accessed 24 Sep 2019.

20. ClinicalTrials.gov. A study to compare the bioavailability of $300 \mathrm{mg}$ trazodone hydrochloride extended-release caplets and $100 \mathrm{mg}$ trazodone hydrochloride immediate-release tablets (administered three times daily). https://clinicaltrials.gov/ct2/ show/NCT01121900. Accessed 24 Sep 2019.

21. European Medicines Agency. Guideline on bioanalytical method validation. https://www.ema.europa.eu/en/documents/ scientific-guideline/guideline-bioanalytical-methodvalidation_en.pdf. Accessed 14 May 2012.

22. Karhu D, Gossen ER, Mostert A, Cronjé T, Fradette C. Safety, tolerability, and pharmacokinetics of once-daily trazodone extended-release caplets in healthy subjects. Int J Clin Pharmacol Ther. 2011;49:730-43. https://doi.org/10.5414/ cp201546.

23. Anwar S, Fell JT, Dickinson PA. An investigation of the disintegration of tablets in biorelevant media. Int $\mathrm{J}$ Pharm. 2005;290:121-7. https://doi.org/10.1016/j.ijpharm.2004.11.023.

24. Ikeuchi SY, Kambayashi A, Kojima H, Oku N, Asai T. Prediction of the oral pharmacokinetics and food effects of gabapentin enacarbil extended-release tablets using biorelevant dissolution tests. Biol Pharm Bull. 2018;41:1708-15. https:// doi.org/10.1248/bpb.b18-00456.

25. Abrahamsson B, Albery T, Eriksson A, Gustafsson I, Sjöberg M. Food effects on tablet disintegration. Eur J Pharm Sci. 2004;22:165-72. https://doi.org/10.1016/j.ejps.2004.03.004.

26. Kalantzi L, Polentarutti B, Albery T, Laitmer D, Abrahamsson B, Dressman J, et al. The delayed dissolution of paracetamol products in the canine fed stomach can be predicted in vitro but it does not affect the onset of plasma levels. Int $\mathrm{J}$ Pharm. 2005;296:87-93. https://doi.org/10.1016/j.ijpharm.2005.02.028.

27. Schneider F, Grimm M, Koziolek M, Modeß C, Dokter A, Roustom $\mathrm{T}$, et al. Resolving the physiological conditions in bioavailability and bioequivalence studies: comparison of fasted and fed state. Eur J Pharm Biopharm. 2016;108:214-9. https:// doi.org/10.1016/j.ejpb.2016.09.009.

28. Koziolek M, Grimm M, Becker D, Iordanov V, Zou H, Shimizu $\mathrm{J}$, et al. Investigation of $\mathrm{pH}$ and temperature profiles in the GI tract of fasted human subjects using the Intellicap( $($ ) $)$ system. J Pharm Sci. 2015;104:2855-63. https://doi.org/10.1002/jps.24274.

29. Abrahamsson B, Pal A, Sjöberg M, Carlsson M, Laurell E, Brasseur JG. A novel in vitro and numerical analysis of shearinduced drug release from extended-release tablets in the fed stomach. Pharm Res. 2005;22:1215-26. https://doi.org/10.1007/ s11095-005-5272-x.

30. Abrahamsson B, Alpsten M, Hugosson M, Jonsson UE, Sundgren M, Svenheden A, et al. Absorption, gastrointestinal transit, and tablet erosion of felodipine extended-release (ER) tablets. Pharm Res. 1993;10:709-14. https://doi.org/10.1023/ A:1018959732744.

31. Cassilly D, Kantor S, Knight LC, Maurer AH, Fisher RS, Semler J, et al. Gastric emptying of a non-digestible solid: assessment with simultaneous SmartPill $\mathrm{pH}$ and pressure capsule, antroduodenal manometry, gastric emptying scintigraphy. Neurogastroenterol Motil. 2008;20:311-9. https://doi.org/ 10.1111/j.1365-2982.2007.01061.x.

32. Conti S, Maggi L, Segale L, Ochoa Machiste E, Conte U, Grenier P, et al. Matrices containing NaCMC and HPMC 1. Dissolution performance characterization. Int $\mathrm{J}$ Pharm. 2007;333:136-42. https://doi.org/10.1016/j.ijpharm.2006.11.059.

33. Conti S, Maggi L, Segale L, Ochoa Machiste E, Conte U, Grenier P, et al. Matrices containing NaCMC and HPMC 2. Swelling and release mechanism study. Int J Pharm. 2007;333:143-51. https://doi.org/10.1016/j.ijpharm.2006.11.067.

34. Nokhodchi A, Raja S, Patel P, Asare-Addo K. The role of oral controlled release matrix tablets in drug delivery systems. BioImpacts BI. 2012;2:175-87. https://doi.org/10.5681/ bi.2012.027.

35. Franek F, Holm P, Larsen F, Steffansen B. Interaction between fed gastric media (Ensure Plus $\left.{ }^{\circledR}\right)$ and different hypromellose based caffeine controlled release tablets: comparison and mechanistic study of caffeine release in fed and fasted media versus water using the USP dissolution apparatus 3 . Int $\mathrm{J}$ Pharm. 2014;461:419-26. https://doi.org/10.1016/ j.ijpharm.2013.12.003.

36. Košir D, Ojsteršek T, Baumgartner S, Vrečer F. A study of critical functionality-related characteristics of HPMC for sustained-release tablets. Pharm Dev Technol. 2018;23:865-73. https://doi.org/10.1080/10837450.2016.1264417.

37. Zhou D, Law D, Reynolds J, Davis L, Smith C, Torres JL, et al. Understanding and managing the impact of HPMC variability on drug release from controlled release formulations. J Pharm Sci. 2014;103:1664-72. https://doi.org/10.1002/jps.23953. 
38. Thoorens G, Krier F, Leclercq B, Carlin B, Evrard B. Microcrystalline cellulose, a direct compression binder in a quality by design environment-a review. Int J Pharm. 2014;473:64-72. https://doi.org/10.1016/j.ijpharm.2014.06.055.

39. Luukkonen P, Schaefer T, Hellén L, Juppo AM, Yliruusi J. Rheological characterization of microcrystalline cellulose and silicified microcrystalline cellulose wet masses using a mixer torque rheometer. Int J Pharm. 1999;188:181-92. https://doi.org/ 10.1016/s0378-5173(99)00219-7.

40. Jaipal A, Pandey MM, Charde SY, Raut PP, Prasanth KV, Prasad RG. Effect of HPMC and mannitol on drug release and bioadhesion behavior of buccal discs of buspirone hydrochloride: in-vitro and in-vivo pharmacokinetic studies. Saudi Pharm J SPJ. 2015;23:315-26. https://doi.org/10.1016/j.jsps.2014.11.012.

41. Marchetti M, Mariotti F, Ragni L, Scarpetti P, Valenti M. Stable liquid pharmaceutical composition based on trazodone https:// patents.google.com/patent/WO2009016069A2/en. .

42. Rejestr Produktów Leczniczych. Trittico XR. Rejestr Produktów Lecz. https://pub.rejestrymedyczne.csioz.gov.pl/ ProduktSzczegoly.aspx?id=30628. Accessed 31 Oct 2019.

43. Ispas-Szabo P, Ravenelle F, Hassan I, Preda M, Mateescu MA. Structure-properties relationship in cross-linked high-amylose starch for use in controlled drug release. Carbohydr Res. 2000;323:163-75. https://doi.org/10.1016/s0008-6215(99)00250-5.

44. Rahmouni M, Chouinard F, Nekka F, Lenaerts V, Leroux JC. Enzymatic degradation of cross-linked high amylose starch tablets and its effect on in vitro release of sodium diclofenac. Eur J Pharm Biopharm Off J Arbeitsgemeinschaft Pharm Verfahrenstechnik EV. 2001;51:191-8.

45. Lenaerts V, Moussa I, Dumoulin Y, Mebsout F, Chouinard F, Szabo P, et al. Cross-linked high amylose starch for controlled release of drugs: recent advances. J Control Release. 1998;53:225-34. https://doi.org/10.1016/s0168-3659(97)00256-3.

46. Koziolek M, Alcaro S, Augustijns P, Basit AW, Grimm M, Hens $\mathrm{B}$, et al. The mechanisms of pharmacokinetic food-drug interactions - a perspective from the UNGAP group. Eur J Pharm Sci. 2019;134:31-59. https://doi.org/10.1016/ j.ejps.2019.04.003.

47. Grimm M, Scholz E, Koziolek M, Kühn J-P, Weitschies W. Gastric water emptying under fed state clinical trial conditions is as fast as under fasted conditions. Mol Pharm. 2017;14:4262-71. https://doi.org/10.1021/acs.molpharmaceut.7b00623.

48. Weitschies W, Wedemeyer R-S, Kosch O, Fach K, Nagel S, Söderlind E, et al. Impact of the intragastric location of extended release tablets on food interactions. J Control Release. 2005;108:375-85. https://doi.org/10.1016/ j.jconrel.2005.08.018.

Publisher's Note Springer Nature remains neutral with regard to jurisdictional claims in published maps and institutional affiliations. 